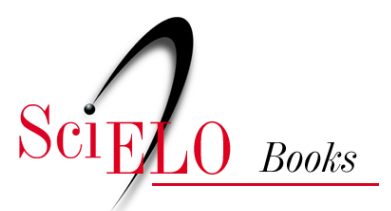

\title{
Guerra do Contestado
}

\author{
José Carlos Radin \\ Gentil Corazza
}

\section{SciELO Books / SciELO Livros / SciELO Libros}

RADIN, J.C., and CORAZZA, G. Guerra do Contestado. In: Dicionário histórico-social do Oeste catarinense [online]. Chapecó: Editora UFFS, 2018, pp. 79-83. ISBN: 978-85-64905-65-8.

https://doi.org/10.7476/9788564905658.0018.

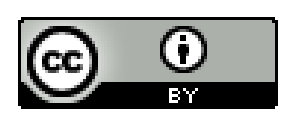

All the contents of this work, except where otherwise noted, is licensed under a Creative Commons Attribution 4.0 International license.

Todo o conteúdo deste trabalho, exceto quando houver ressalva, é publicado sob a licença Creative Commons Atribição $\underline{4.0}$.

Todo el contenido de esta obra, excepto donde se indique lo contrario, está bajo licencia de la licencia $\underline{\text { Creative Commons }}$ Reconocimento 4.0. 


\section{Guerra do Contestado}

A Guerra do Contestado foi um conflito armado, ocorrido entre outubro de 1912 e agosto de 1916, que confrontou, de um lado, a população sertaneja e, do outro, as forças do governo estadual e federal, em terras do Oeste paranaense e catarinense. A guerra ocorreu num contexto histórico-geográfico e social conturbado por uma série de conflitos, como foi a questão dos limites entre Brasil e Argentina, bem como a disputa das terras contestadas entre os estados de Santa Catarina e do Paraná, além da expropriação das terras e expulsão da população cabocla, que vivia na região. Some-se a isso o coronelismo dominante na região, o impacto e as consequências da construção da estrada de ferro São Paulo-Rio Grande, que expropriou terras e deslocou milhares de sertanejos, e a herança de conflitos ligados principalmente à Revolução Federalista de 1893, que impactou fortemente o planalto catarinense. A pregação religiosa e social dos monges também contribuiu como elemento catalisador do descontentamento e da revolta dos sertanejos, fazendo-a tomar forma de uma "guerra santa". Somado a esse conjunto de problemas sociais, decorrentes principalmente da falta de regularização da posse de terras e da insatisfação da população da região, está a quase inexistência do poder público na região.

A tropa oficial envolvida na guerra chegou a ter 7 mil pessoas, as quais representavam mais de um terço do exército republicano brasileiro, além de policiais de Santa Catarina e do Paraná e capangas arregimentados pelos fazendeiros. Pela primeira vez, também, na América do Sul, foi utilizada a aviação com fins bélicos. Do outro lado, o contingente das forças rebeldes chegava a somar milhares de combatentes, variando de acordo com as circunstâncias. O total de mortos em consequência dos combates, da fome e das epidemias pode ter sido superior a 10 mil. (MACHADO, 2012). O fim do conflito foi selado pelo Acordo dos Limites, presidido pelo Presidente da República, Wenceslau Brás, e assinado em 20 de outubro de 1916 pelos governadores de Santa Catarina, Felipe Schmidt, e do Paraná, Afonso Camargo. 
Na comunidade de Taquaruçu, um grupo de sertanejos reunidos em torno do monge José Maria, ao ser perseguido pela polícia catarinense, refugiou-se na localidade de Irani, ao Oeste, em território reivindicado pelo Paraná, cujas autoridades consideraram uma invasão catarinense em seu território. $\mathrm{O}$ ataque da polícia paranaense ao grupo de sertanejos, em 22 de outubro de 1912, ficou conhecido como a Batalha do Irani, a qual marcou o início da Guerra do Contestado. Nessa batalha morreram 11 sertanejos, inclusive o monge José Maria, e 10 soldados, incluindo o comandante das forças paranaenses, João Gualberto Gomes de Sá.

A Batalha do Irani foi considerada como uma primeira vitória contra as forças governamentais. Para os sertanejos, o monge José Maria, símbolo da luta pela posse da terra, não morreu, ele continua encantado no meio do povo. A crença de que ele voltaria para guiar seu povo até a vitória final passou a alimentar o reagrupamento da população sertaneja. Um ano depois da morte do monge, a menina Teodora, de 11 anos, passou a ter visões e a receber mensagens do monge, que pedia para seus seguidores se reunirem em Taquaruçu. O agrupamento efetivo inicia em dezembro de 1913 e transforma-se em uma "cidade santa”. A partir do exemplo de Taquaruçu, formaram-se inúmeras outras "cidades santas", como Caraguatá, Santo Antônio e Santa Maria, a maior delas, que chegou a reunir mais de 20 mil pessoas. As "cidades santas" eram verdadeiras comunidades que se transformaram em fortes redutos sertanejos. Em muitas delas, chegou-se mesmo a organizar alguma forma de "comunismo caboclo".

No início de 1914, tropas conjuntas de Santa Catarina, Paraná e do governo federal, com um efetivo de 700 soldados, atacam o reduto de Taquaruçu, incendeiam o acampamento, mas os sertanejos fogem e se refugiam no acampamento de Caraguatá. Esse reduto se formou sob a liderança de Maria Rosa, uma jovem de quinze anos, que a exemplo da menina Teodora, também dizia ter visões e receber mensagens do monge. Maria Rosa é considerada por muitos como uma Joana D'Arc sertaneja. Em 9 de março de 1914, as tropas oficiais cercam e atacam Caraguatá, mas são derrotadas pelos caboclos. A vitória atrai novos caboclos para o reduto e reforça a luta contra as tropas oficiais. A partir 
daí os sertanejos partem para a ofensiva, saqueando fazendas de coronéis e atacando cidades, numa espécie de "guerra santa". No ataque a Curitibanos, um dos alvos foram os cartórios onde se encontravam os registros das terras que estavam em posse dos caboclos e lhes haviam sido tiradas. Na localidade de Calmon, foi incendiada e destruída uma serraria da Lumber, um dos símbolos da presença estrangeira na região. O governo federal mostrava-se cada vez mais preocupado com a dimensão da revolta sertaneja e o clima de guerra que tomava conta da região. O general Mesquita, veterano de Canudos, é nomeado para comandar as ações contra os rebeldes. $\mathrm{O}$ ataque ao reduto de Santo Antônio e uma epidemia de tifo no reduto de Caraguatá obrigam os revoltosos a fugirem e a se dispersarem. No entanto, os sertanejos voltam a reorganizar-se na localidade de Santa Maria. O comandante das forças oficiais tinha ordens para sufocar a rebelião e pacificar a região a qualquer custo, mas, em vez do ataque direto, ele adota a estratégia de cercar os redutos e cortar o abastecimento, na expectativa de conseguir a rendição dos rebelados. É nessas circunstâncias que começa a destacar-se a figura e a liderança de Deodato Manuel Ramos, mais conhecido por Adeodato, considerado pelos historiadores como o último líder dos sertanejos. Adeodato transfere o núcleo dos revoltosos para o vale de Santa Maria, que chega a reunir mais de 20 mil pessoas. Com o aperto do cerco aos rebeldes, os problemas internos agravam-se e eles não podem resistir por muito tempo. Nos primeiros meses de 1915, são feitos diversos ataques ao reduto de Santa Maria e a outros agrupamentos. Em dezembro de 1915, todos os redutos rebeldes haviam sido destruídos, mas o final da guerra só se efetiva de fato com o término do litígio dos limites entre Paraná e Santa Catarina, em 20 de outubro de 1916.

Parte da imprensa, setores governamentais e a opinião pública da época apontaram como causa do conflito a ignorância e o fanatismo da população cabocla, que seguia a orientação do monge José Maria (WELTER, 2007). Depois da batalha de Taquaruçu, em fevereiro de 1914, o movimento chegou mesmo a ser denominado de banditismo, jaguncismo e fanatismo. No entanto, as razões da guerra foram mais amplas e complexas. Tratava-se de um verdadeiro movimento social 
(MACHADO, 2001) ou mesmo do "maior conflito social brasileiro envolvendo questões fundiárias" (VALENTINI, 2015). Embora tenha começado como um fenômeno religioso, de exaltação milenar, com fortes características messiânicas e místicas, associadas à morte de seu principal líder, o monge José Maria, e à crença na sua volta, esse movimento reuniu diferentes segmentos sociais, como posseiros, sitiantes expulsos de suas terras, comunidades negras e caboclas, ervateiros, desempregados da estrada de ferro, médios fazendeiros, antigas lideranças federalistas e opositores dos coronéis.

Esse conflito armado tem duas faces, uma "guerra santa", de um lado, e uma "guerra sertaneja", de outro. Ou seja, uma face religiosa, messiânica e mística e outra face crítica e social, as quais tiveram pesos variáveis, dependendo das circunstâncias. Mesmo que o discurso oficial tenha sido a "guerra santa", linguagem geral da rebelião, o motivo religioso não esgotava as razões da guerra, pois os sertanejos tinham plena consciência contra quais forças estavam lutando. Seus alvos eram os chefes políticos locais, os grandes fazendeiros, os interesses estrangeiros e a marginalização sertaneja. Os sertanejos desenvolveram "uma nítida consciência das condições sociais e políticas de sua marginalização" (MACHADO, 2001). Para eles, tratava-se de uma "guerra entre ricos e pobres", que lutavam contra um governo que "defendia os interesses dos endinheirados, dos coronéis e dos estrangeiros".

O nome "contestado" está relacionado a vários fatos, como a contestação de caboclos e agricultores pelo fato de suas terras terem sido apropriadas pelas madeireiras, como foi o caso da Lumber, pelas terras serem disputadas, primeiro pelo Brasil e Argentina e depois pelos estados do Paraná e de Santa Catarina. Embora o conflito tenha se travado na sua maior parte em terras catarinenses não contestadas, ele ficou consagrado, inicialmente, pelos relatos militares e depois pela maior parte da literatura como Guerra do Contestado. Mas o conflito dos limites entre os estados do Paraná e de Santa Catarina e suas reivindicações pelo "território contestado" não influíram senão indiretamente na Guerra do Contestado. Para Machado (2001), o nome mais adequado seria "Guerra Sertaneja do Contestado". 
Outra questão se refere à defesa da monarquia feita pelo movimento sertanejo rebelde. Como muitos outros movimentos sociais rurais brasileiros, o movimento sertanejo rebelde do Contestado também fez a defesa do regime monárquico de governo. Uma espécie de "monarquismo sertanejo" passou a fazer parte dos objetivos dos seguidores do monge José Maria. Uma das razões para a exaltação do regime monárquico foi que muitos dos males vividos pelos sertanejos da região atingida pela guerra eram atribuídos ao regime e às políticas do governo republicano. Os sertanejos desamparados pelo governo republicano pareciam sentir uma proteção paternal do monarca. Para eles, a Monarquia era uma forma divina superior de organização social. A Monarquia é vista como o regime da "lei de Deus", e a República é associada à lei do diabo e ao poder dos coronéis.

Por longo tempo, a Guerra do Contestado permaneceu no esquecimento. Os relatos militares foram sua principal memória, até que, nas décadas de 1960 e 1970, o tema se tornou objeto de inúmeras pesquisas acadêmicas. $O$ trabalho de Valentini (2015) oferece uma ampla e diversificada bibliografia sobre aquele que foi talvez o maior conflito social e bélico travado no Brasil.

\section{REFERENCIAS}

KARSBURG, Alexandre de Oliveira. O Eremita do Novo Mundo: A trajetória de um peregrino italiano na América do século XIX (1838-1869). (Tese de Doutorado) Rio de Janeiro: UFRJ, 2012.

MACHADO, Paulo P. Um Estudo Sobre as Origens Sociais e a Formação Política das Lideranças Sertanejas do Contestado, 1912 - 1916. (Tese de Doutorado) Campinas: Unicamp/História, 2001. . Guerra do Contestado: os reflexos cem anos depois. Entrevista.

Revista IHU, São Leopoldo: Unisinos, 15 de outubro de 2012.

VALENTINI, Delmir José. A Guerra do Contestado (1912-1916). In:

RADIN, J.C; VALENTINI, D. J.; ZARTH, P. A. História da Fronteira Sul. Porto Alegre: Letra e Vida, 2015.

WELTER, Tânia. O Profeta São João Maria continua encantando no meio do povo: um estudo sobre os discursos contemporâneos a respeito de João Maria em Santa Catarina(Tese de Doutorado). Florianópolis: UFSC, 2007. 